\title{
Effect of Sodium-Glucose Cotransporter 2 Inhibitors on Weight Reduction in Overweight and Obese Populations without Diabetes: A Systematic Review and a Meta-Analysis
}

\author{
Yun Kyung Cho', Ye-Jee Kim², Chang Hee Jung ${ }^{3,4, *}$ \\ ${ }^{1}$ Department of Internal Medicine, Hallym University Sacred Heart Hospital, Hallym University College of Medicine, Anyang; Departments of ${ }^{2}$ Clinical Epidemiology \\ and Biostatistics and ${ }^{3}$ Internal Medicine, Asan Medical Center, University of Ulsan College of Medicine, Seoul; ${ }^{4}$ Asan Diabetes Center, Asan Medical Center, Seoul, \\ Korea
}

Background: We aimed to evaluate the efficacy of sodium-glucose cotransporter 2 (SGLT2) inhibitors for managing obesity in non-diabetic overweight or obese patients.

Methods: For purposes of this study, PubMed, Embase, Web of Science, and the Cochrane Central Register of Controlled Trials were searched through May 2021. Randomized controlled trials published in English that compared SGLT2 inhibitors with placebo in overweight and obese patients without diabetes were included in the primary analysis. The random effects standardized mean difference $\pm 95 \%$ confidence interval $(95 \% \mathrm{Cl})$ was calculated as the effect size.

Results: Five randomized controlled trials were included to evaluate body weight change, four trials to assess body mass index (BMI), and three trials to assess waist circumference were included. Results showed that the mean body weight loss on SGLT2 inhibitors in obese patients without diabetes was $-1.62 \mathrm{~kg}(95 \% \mathrm{Cl},-2.38$ to $-0.85 \mathrm{~kg}$ ) when compared with placebo. Treatment with SGLT2 inhibitors was also associated with a greater reduction in BMl than placebo (weighted mean difference, $-0.47 \mathrm{~kg} / \mathrm{m}^{2} ; 95 \% \mathrm{Cl},-0.62$ to $-0.31 \mathrm{~kg} / \mathrm{m}^{2}$ ). The mean reduction in waist circumference with SGLT2 inhibitors versus placebo was $1.29 \mathrm{~cm}(95 \% \mathrm{Cl},-2.62$ to $0.04 \mathrm{~cm})$, which was not statistically significant. There were no significant changes in fat mass, blood pressure, low-density lipoprotein cholesterol or high-density lipoprotein cholesterol with SGLT2 inhibitor treatment.

Conclusion: A meta-analysis demonstrated that although the weight lowering effect was mild, SGLT2 inhibitors significantly reduced body weight in obese patients without diabetes.

Key words: Diabetes mellitus, Obesity, Sodium-glucose transporter 2 inhibitors

\author{
Received July 19, 2021 \\ Reviewed October 13, 2021 \\ Accepted October 14, 2021 \\ ${ }^{*}$ Corresponding author \\ Chang Hee Jung \\ https://orcid.org/0000-0003-4043-2396 \\ Department of Internal Medicine, Asan \\ Medical Center, University of Ulsan \\ College of Medicine, 88 Olympic-ro \\ 43-gil, Songpa-gu, Seoul 05505, Korea \\ Tel: +82-2-3010-1418 \\ Fax: +82-2-3010-6962 \\ E-mail:chjung0204@gmail.com
}

\section{INTRODUCTION}

Obesity is a worldwide health concern that has become epidemic in recent decades. Over a third of individuals worldwide were classified as overweight or obese in 2016, with obesity incidence exceeding 50\% in certain countries. ${ }^{1.3}$ From 2009 through 2018 the prevalence of obesity in the entire population in Korea grew, with the prevalence reaching $35.7 \%$ in $2018 .{ }^{1}$ Obesity and overweight are associated with significantly increased risk of developing a variety of cardiometabolic diseases, including type 2 diabetes (T2D), hypertension, dyslipidemia, heart disease, and several kinds of cancer. ${ }^{4-6}$ Additionally, obesity is associated with a variety of musculoskeletal, pulmonary, renal, gastrointestinal, and mental problems. ${ }^{4,7,8}$ Although the cornerstone management for obesity is lifestyle change,

Copyright (C) 2021 Korean Society for the Study of Obesity

(a) This is an Open Access article distributed under the terms of the Creative Commons Attribution Non-Commercial License (https://creativecommons.org/licenses/by-nc/4.o/) which permits unrestricted non-commercial use, distribution, and reproduction in any medium, provided the original work is properly cited. 
primarily reducing calorie consumption and increasing physical activity, the majority of people who are overweight or obese do not attain their desired body weight through lifestyle change alone. Antiobesity drugs may contribute to weight loss; however, some individuals are unable to endure the adverse effects of anti-obesity medications, particularly appetite suppressants. Therefore, additional effective weight-loss treatments are needed.

Sodium-glucose cotransporter 2 (SGLT2) inhibitors are a recently developed class of oral glucose-lowering medications that target the kidneys. These medications increase urinary glucose excretion by inhibiting the reabsorption of glucose from urine in the kidney's proximal tubule. ${ }^{4}$ Although SGLT2 inhibitors are primarily prescribed to treat $\mathrm{T} 2 \mathrm{D}$, they also result in weight loss, which is predominantly accounted for by fat loss. ${ }^{4}$ Since the amount of resultant glucosuria is proportional to plasma glucose over threshold, calorie excretion is also increased as the level of glucose in plasma increases, implying that weight reduction by SGLT2 inhibitor might be more effective in individuals with T2D. ${ }^{9}$ However, several clinical trials have recently revealed that SGLT2 inhibitors significantly lowered body weight relative to placebo, even in overweight or obese patients without T2D. As such, the purpose of the present study was to comprehensively evaluate the effect of an SGLT2 inhibitor on weight reduction of overweight in obese patients without T2D.

\section{METHODS}

\section{Search strategy and study selection}

A literature search of four databases was conducted: PubMed, Embase, Web of Science, and the Cochrane Central Register of Controlled Trials, to obtain a comprehensive list of trials from their inception to May 2021, to identify eligible randomized controlled trials (RCTs) involving SGLT2 inhibitors in overweight and obese patients without diabetes. The main keywords used were "nondiabetic or without diabetes," "obesity or overweight," and "SGLT2 inhibitors." The search terms in detail are shown in Supplementary Table 1.

RCTs that compared SGLT2 inhibitors with placebo in overweight and obese patients without diabetes were included. RCTs published in English that included information on the change in body weight from baseline were eligible for inclusion. Titles of the

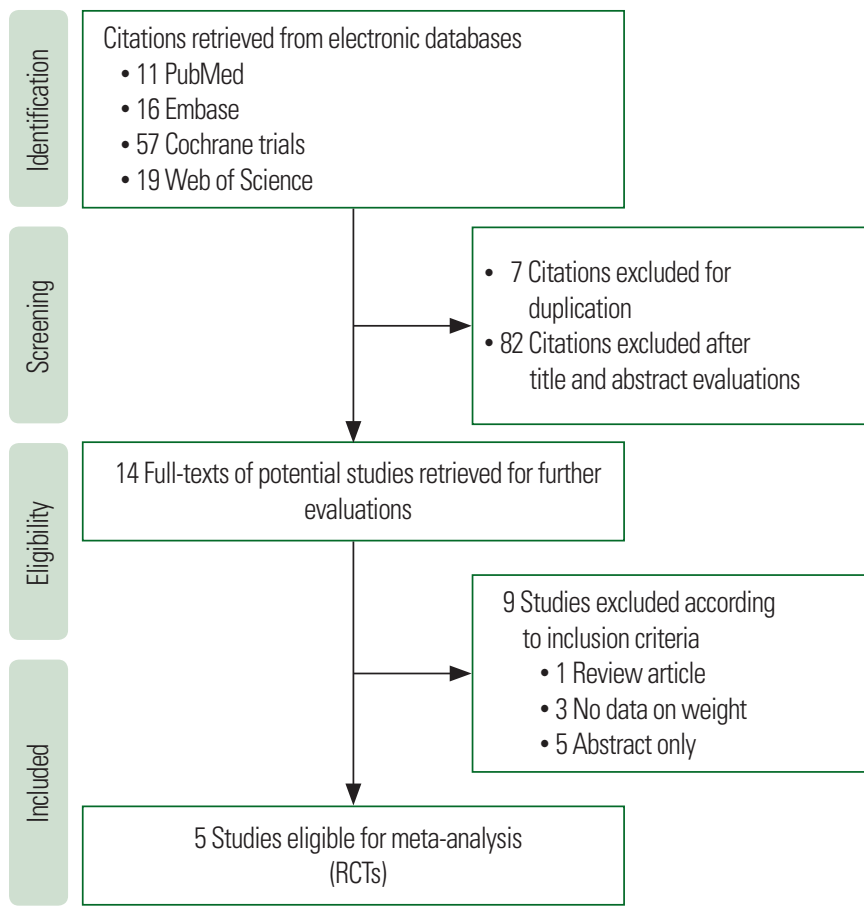

Figure 1. Flow diagram of the study selection process. RCT, randomized controlled trial.

studies, abstracts, and full manuscripts were reviewed to confirm that the studies met the inclusion criteria. Two authors (YKC and $\mathrm{CHJ}$ ) worked independently to review the studies and eventually agreed on the list of studies to include. Fig. 1 depicts flowcharts for the study selection process.

\section{Data extraction}

The primary outcome of the present analysis was change in body weight from baseline to the final endpoint of each study. Secondary outcomes were changes in body mass index (BMI), waist circumference (WC), fat mass, systolic blood pressure, diastolic blood pressure, low-density lipoprotein cholesterol (LDL-C), and highdensity lipoprotein cholesterol (HDL-C) from baseline. Hypoglycemia events were also evaluated as a secondary outcome. Along with outcome measurements, the two authors (YKC and $\mathrm{CHJ}$ ) independently gathered information on the authors and publication year; the number of research participants; and their age, sex, body weight, and BMI at baseline and finally integrated the data. In terms of outcomes, the mean difference between baseline and end measures was determined for each group, together with the standard deviation of their variability. 
Table 1. Characteristics of the studies included in the systematic review and meta-analysis

\begin{tabular}{|c|c|c|c|c|c|c|c|}
\hline Author & Medication & Duration & $\mathrm{n}$ & Age (yr) & Men (\%) & Body weight (kg) & $\mathrm{BMI}\left(\mathrm{kg} / \mathrm{m}^{2}\right)$ \\
\hline \multirow[t]{4}{*}{ Bays et al. $(2014)^{18}$} & Placebo & $12 \mathrm{wk}$ & 89 & $45.1 \pm 11.9$ & 16.0 & $102.2 \pm 19.9$ & $36.6 \pm 5.5$ \\
\hline & Canagliflozin 50 mg OD & & 98 & $44.9 \pm 11.8$ & 12.0 & $98.1 \pm 16.0$ & $36.6 \pm 5.3$ \\
\hline & Canagliflozin 100 mg OD & & 85 & $45.8 \pm 11.0$ & 18.0 & $105.0 \pm 16.6$ & $37.9 \pm 5.1$ \\
\hline & Canagliflozin 300 mg QD & & 96 & $43.5 \pm 11.0$ & 10.0 & $100.2 \pm 18.0$ & $36.9 \pm 5.3$ \\
\hline \multirow{3}{*}{$\begin{array}{l}\text { Napolitano et al. } \\
(2013)^{19}\end{array}$} & Placebo & $8 w k$ & 11 & $42.0 \pm 13.0$ & 73.0 & $101.0 \pm 14.6$ & $33.0 \pm 2.4$ \\
\hline & Remogliflozin etabonate $250 \mathrm{mg}$ TID & & 8 & & & & \\
\hline & Sergliflozin etabonate $1,000 \mathrm{mg}$ TID & & 8 & & & & \\
\hline \multirow{2}{*}{$\begin{array}{l}\text { Hollander et al. } \\
(2017)^{20}\end{array}$} & Placebo & $26 w k$ & 76 & $44.8 \pm 11.1$ & 18.3 & $104.3 \pm 18.2$ & $38.0 \pm 5.2$ \\
\hline & Canagliflozin 300 mg QD & & 78 & $45.2 \pm 11.0$ & 19.0 & $103.3 \pm 19.1$ & $37.3 \pm 4.7$ \\
\hline \multirow[t]{2}{*}{ He et al. $(2019)^{21}$} & Placebo & $12 w k$ & 44 & $40.2 \pm 11.5$ & 48.9 & $115.7 \pm 19.0$ & $40.2 \pm 3.6$ \\
\hline & Licogliflozin 150 mg QD & & 44 & & & & \\
\hline \multirow{2}{*}{$\begin{array}{l}\text { Faerch et al. } \\
(2021)^{22}\end{array}$} & Placebo & 26 wk & 27 & $57.2 \pm 9.9$ & 40.0 & Men, $99.0 \pm 15.1$; women, $92.1 \pm 25.3$ & Men, $33.2 \pm 4.3$; women, $31.8 \pm 3.4$ \\
\hline & Dapagliflozin 10 mg OD & & 28 & $61.4 \pm 8.5$ & 43.0 & Men, 103.7 \pm 17.6; women, $82.5 \pm 13.7$ & Men, 31.6 \pm 3.8 ; women, $30.4 \pm 5.1$ \\
\hline
\end{tabular}

Values are presented as mean \pm standard deviation.

$\mathrm{BMI}$, body mass index; $\mathrm{OD}$, once a day; $\mathrm{TID}$, three times a day.

\section{Assessment of methodological quality}

We evaluated the quality of the included RCTs based on the Cochrane Collaboration's tool for assessing the risk of bias. ${ }^{10}$ Supplementary Fig. 1 shows summaries of the risk of bias assessment.

\section{Statistical analysis}

We calculated pooled estimates of the weighted mean differences (WMDs) and 95\% confidence intervals (CIs) for the outcomes and applied a random effects model to account for the variability across the included studies by using a restricted maximum likelihood estimate of the between-studies variance. The $\mathrm{I}^{2}$ statistic was used to assess the magnitude of the heterogeneity between studies and the extent of heterogeneity was estimated as follows: low (25\%), moderate (50\%), and high (75\%) I $\mathrm{I}^{2}$ values. ${ }^{11}$ The potential risk of publication bias was evaluated by constructing funnel plots of the primary outcome, and asymmetry was assessed by using Egger's test. Stata version 11.0 (StataCorp., College Station, TX, USA) was used for all analyses.

\section{RESULTS}

\section{Search results and characteristics}

The electronic literature search yielded 103 citations, of which five suitable RCTs including 692 individuals randomized into SGLT2 inhibitor or placebo groups were eventually included in the meta-analysis. Fig. 1 depicts flowcharts of the study selection process, and Table 1 lists the characteristics of the selected studies.

\section{Pooled outcomes in body weight and WC}

In nondiabetic participants with overweight or obesity, the random effects model showed that the administration of SGLT2 inhibitor was associated with a greater reduction in body weight than placebo (WMD, $-1.62 \mathrm{~kg}$; 95\% CI, -2.38 to $-0.85 \mathrm{~kg}$ ) (Fig. 2). The effect was significant after adjustment for study duration and gender (adjusted WMD, $-2.24 \mathrm{~kg} ; 95 \% \mathrm{CI},-4.48$ to $-0.01 \mathrm{~kg}$ ). The forest plot shows that the weight reduction by SGLT2 inhibitor was observed consistently among the studies, although some studies showed statistically non-significant results (Fig. 2). The funnel plot and Egger's test revealed no apparent asymmetry in the distribution or small study effect (Supplementary Fig. 2). However, this finding could not clearly demonstrate the absence of publication bias, due to the limited number of papers included and moderate heterogeneity ( $\mathrm{I}^{2}$ value, $60.9 \%$ ).

Among the included studies, only four reported a change in BMI and three a change in WC from baseline (Figs. 3 and 4). Treatment with SGLT2 inhibitor was associated with a greater reduction in BMI than placebo (WMD, $-0.47 \mathrm{~kg} / \mathrm{m}^{2} ; 95 \% \mathrm{CI},-0.62$ to $-0.31 \mathrm{~kg} / \mathrm{m}^{2}$ ) (Fig. 3). In general, SGLT2 inhibitors showed a trend in decreasing WC compared to placebo in the respective study results and the pooled results from meta-analyses; however, the difference was not 


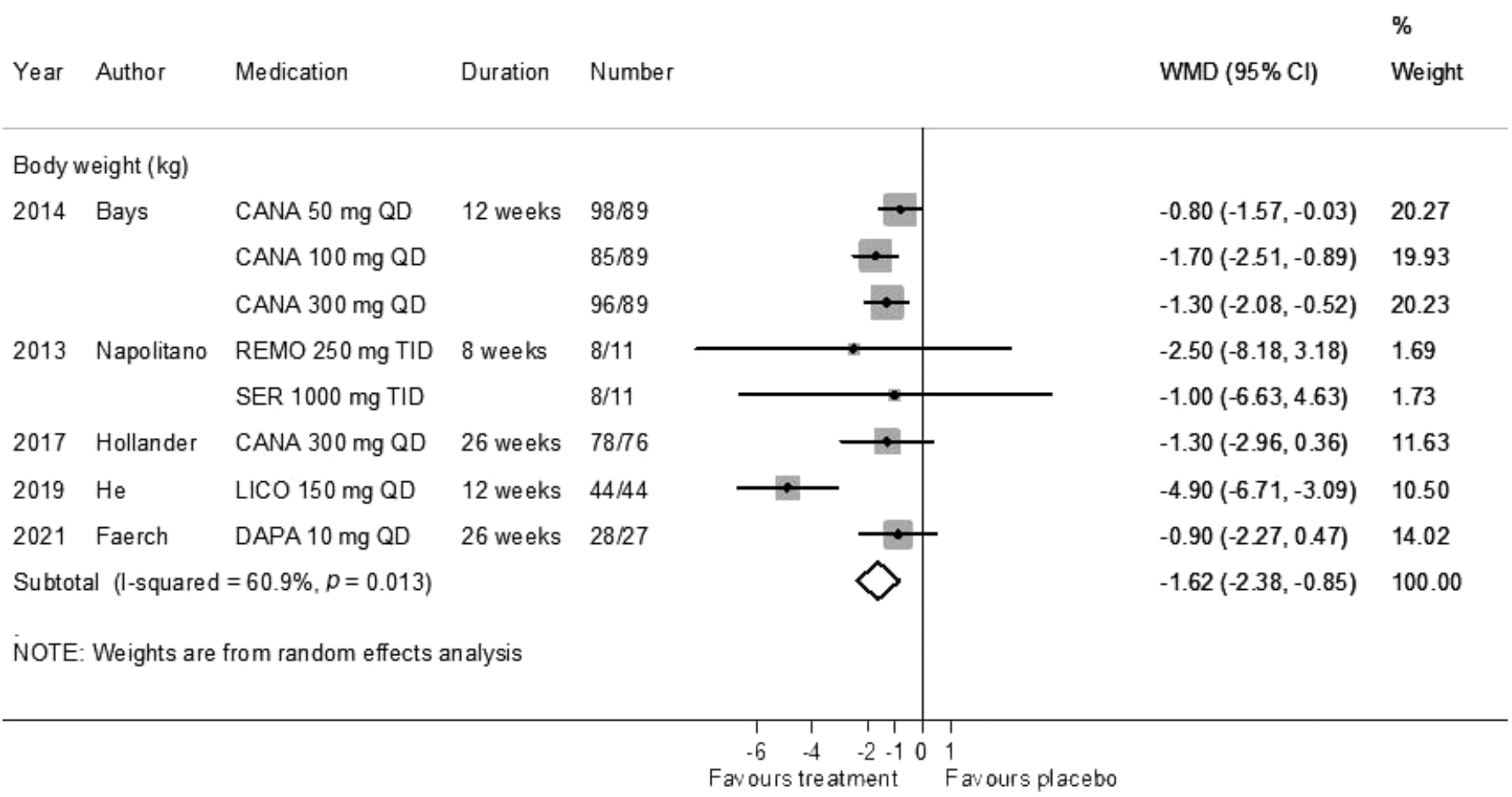

Figure 2. Forest plot of sodium-glucose cotransporter 2 inhibitor-induced body weight reduction compared with placebo. WMD, weighted mean difference; Cl, confidence interval; $\mathrm{QD}$, once a day; $\mathrm{TID}$, three times a day.

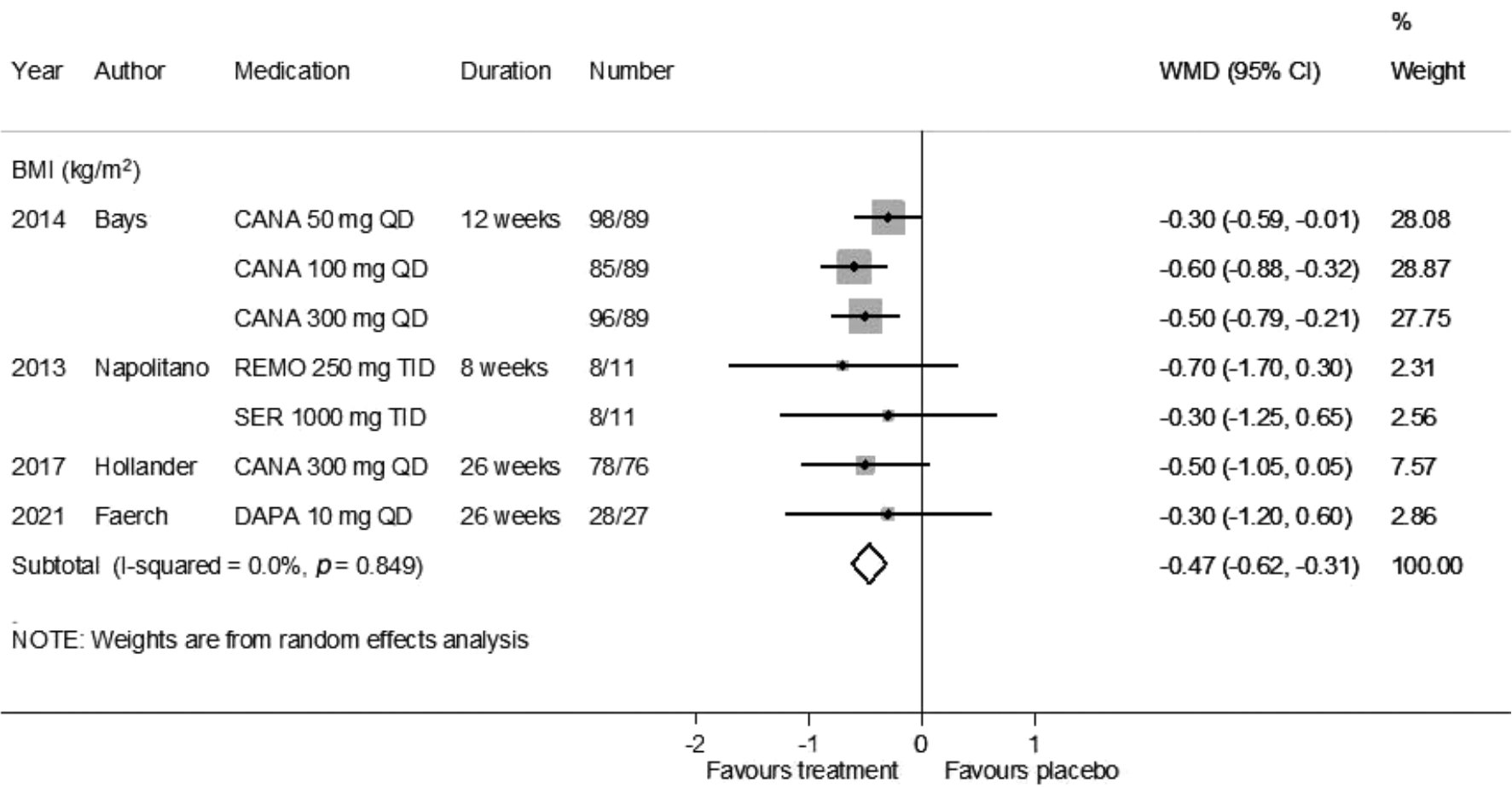

Figure 3. Forest plot of sodium-glucose cotransporter 2 inhibitor-induced reduction in body mass index (BMI) compared with placebo. WMD, weighted mean difference; $\mathrm{Cl}$, confidence interval; $\mathrm{OD}$, once a day; $\mathrm{TID}$, three times a day. 


\begin{tabular}{|c|c|c|c|c|c|c|}
\hline \multirow[b]{2}{*}{ Year } & \multirow[b]{2}{*}{ Author } & \multirow[b]{2}{*}{ Medication } & \multirow[b]{2}{*}{ Duration } & \multirow[b]{2}{*}{ Number } & \multirow[b]{2}{*}{ WMD $(95 \% \mathrm{Cl})$} & $\%$ \\
\hline & & & & & & Weight \\
\hline \multicolumn{7}{|c|}{ Waist circumference $(\mathrm{cm})$} \\
\hline \multirow[t]{3}{*}{2014} & Bays & CANA $50 \mathrm{mg}$ QD & 12 weeks & $98 / 89$ & $-0.20(-2.68,2.28)$ & 28.84 \\
\hline & & CANA $100 \mathrm{mg}$ QD & & $85 / 89$ & $-1.70(-4.96,1.56)$ & 16.66 \\
\hline & & CANA $300 \mathrm{mg}$ QD & & $96 / 89$ & $-1.40(-4.13,1.33)$ & 23.71 \\
\hline \multirow[t]{2}{*}{2013} & Napolitano & REMO $250 \mathrm{mg}$ TID & 8 weeks & $8 / 11$ & $-1.40(-7.77,4.97)$ & 4.35 \\
\hline & & SER $1000 \mathrm{mg}$ TID & & $8 / 11$ & $-1.80(-6.01,2.41)$ & 9.98 \\
\hline 2021 & Faerch & DAPA $10 \mathrm{mg}$ QD & 26 weeks & $28 / 27$ & $-2.30(-5.58,0.98)$ & 16.45 \\
\hline \multicolumn{5}{|c|}{ Subtotal (I-squared $=0.0 \%, p=0.942$ ) } & $-1.29(-2.62,0.04)$ & 100.00 \\
\hline \multicolumn{7}{|c|}{ NOTE: Weights are from random effects analysis } \\
\hline
\end{tabular}

Figure 4. Forest plot of sodium-glucose cotransporter 2 inhibitor-induced reduction in waist circumference compared with placebo. WMD, weighted mean difference; $\mathrm{Cl}$, confidence interval; $\mathrm{QD}$, once a day; $\mathrm{TID}$, three times a day.

statistically significant (WMD, $-1.29 \mathrm{~cm} ; 95 \% \mathrm{CI},-2.62$ to $0.04 \mathrm{~cm})$ (Fig. 4).

Pooled outcomes in fat mass, blood pressure, LDL-C and HDL-C, and hypoglycemic events

Regarding change in fat mass, blood pressure, LDL-C and HDLC, only two studies reported a change from baseline (Supplementary Fig. 3). There were no significant changes in fat mass, blood pressure, LDL-C and HDL-C due to SGLT2 inhibitor use in overweight and obese patients without diabetes. In the combined cohort of 692 patients, hypoglycemia occurred in only five patients (three cases in the SGLT2 inhibitor arm and two cases in the placebo arm).

\section{DISCUSSION}

In this meta-analysis of RCTs including 692 obese or overweight patients without T2D, the study found that treatment with SGLT2 inhibitors led to $1.62 \mathrm{~kg}$ reduction in body weight compared with the placebo. In addition, patients who took SGLT2 inhibitors showed a significant reduction in BMI. WC and fat mass loss by SGLT2 inhibitors was not different from those on placebo. There were no differences in blood pressure, LDL-C and HDL-C. Al- though the weigh-lowering efficacy was not powerful, the metaanalyses demonstrated that SGLT2 inhibitors substantially reduced body weight in non-diabetic obese subjects.

Obesity has become a significant health concern all over the world. ${ }^{12}$ The cornerstone of all weight-loss programs is lifestyle modification; however, nearly every study of lifestyle modification has found that weight loss achieved through lifestyle changes alone is typically limited to $3 \%-10 \%$ of body weight, with the majority of patients regaining at least some of the lost weight within 12 months. ${ }^{13}$ Numerous anti-obesity medications have now been thoroughly studied and verified by regulatory agencies to be safe and effective, from the Food and Drug Administration approval of phentermine in 1959 and to that of liraglutide $3 \mathrm{mg}$ in $2017 .{ }^{12}$ However, prescription rates are still low; this might be due to the frequent side effects associated with most medicines. ${ }^{12}$ Anti-obesity medications, particularly appetite suppressants, do have a variety of adverse effects. ${ }^{12}$ To be sure, existing anti-obesity medications are not as successful as the clinicians and patients expect. ${ }^{12}$ Hence, there is a need for new anti-obesity medicines that are safe and effective, with long durability.

SGLT2 inhibitors are primarily used to treat T2D; however, they also cause body weight reduction, which is predominantly derived from decreased body fat. Furthermore, the body weight reduction 
as well as glycemic effects of these drug class are maintained over several years. ${ }^{14-16}$ A meta-analysis of weight changes in patients receiving SGLT2 inhibitors found that body weight decreased significantly in patients with T2D who received different dosages of various SGLT2 inhibitors, compared to patients who received a placebo. ${ }^{17}$ The meta-analyses included a total of 55 placebo-controlled studies that evaluated the effectiveness of SGLT2 inhibitors to that of placebo in individuals with T2D. ${ }^{17}$ Only a few trials, however, have assessed the impact of SGLT2 inhibitors on weight reduction in obese patients who do not have diabetes. ${ }^{18-22}$

Canagliflozin $100 \mathrm{mg}$ alone lowers body weight by $2.8 \mathrm{~kg}$ in overweight and obese patients without diabetes, according to Bays et al. ${ }^{18}$ However, in another research investigation regarding weight loss with the combination therapy of canagliflozin and phentermine, the reduction in body weight with canagliflozin alone versus placebo (difference, $-1.3 \%$; $95 \% \mathrm{CI},-3.1$ to 0.4 ) did not reach statistical significance. ${ }^{20}$ It should be noted that previous studies on the weightloss effects of the SGLT2 inhibitor in a non-diabetic population have been largely limited in the numbers of participants and the regimens. Thus, we integrated the results from individual studies and elucidated the potential of SGLT2 inhibitors as anti-obesity drugs; overweight or obese patients on SGLT2 inhibitors had a reduction in body weight of $-1.62 \mathrm{~kg}$ and BMI of $-0.47 \mathrm{~kg} / \mathrm{m}^{2}$, without significant change in blood pressure and lipid profile. In addition, hypoglycemia was noted in just five of the study's combined cohort of 692 patients. This implies that SGLT2 inhibitors have a relatively favorable safety profile in those who do not have diabetes.

The following are possible mechanisms by which SGLT2 inhibitors induce weight loss: first, these effects are most likely mediated by calorie loss linked with increased urine glucose excretion (UGE). ${ }^{17}$ It has been reported that treatment of dapagliflozin or canagliflozin resulted in a dose-dependent rise in UGE; however, the maximum effect was typically observed in in patients with T2D. ${ }^{17,23-27}$ Napolitano et al. ${ }^{19}$ extended these findings on the weight lowering effect of SGLT2 inhibitors to obese non-diabetic subjects. There was a statistically significant treatment-related effect of SGLT2 inhibitors, both of remogliflozin and sergliflozin on UGE even in obese individuals without diabetes, while there was no change in glucose excretion in the placebo groups. ${ }^{19}$ Second, the weight reduction seen with SGLT2 inhibitor use might be caused by fat loss. Lipolysis was enhanced and the level of blood ketone body was elevated in dietinduced obese animals in which SGLT2 inhibitors were administered. ${ }^{4,28,29}$ SGLT2 inhibitor-induced glycosuria reduces plasma glucose and insulin levels while increasing fasting and post-meal glucagon concentrations in nondiabetic individuals with obesity; these kinds of hormonal changes might induce the mobilization of stored fat and utilization of it as an energy source. ${ }^{4,30,31}$ However, in this study's meta-analysis, the fat loss due to SGLT2 inhibitors compared to placebo was not significant, possibly due to the limited data source; further studies including a large number of participants are needed. Lastly, the weight loss observed with SGLT2 inhibitor treatment might be associated with an alteration in adipokines related to body weight. The leptin/adiponectin ratio has been recommended as a marker of insulin resistance in non-diabetics, ${ }^{32}$ and there was a significant decrease in this ratio after remogliflozin treatment, implying that this type of SGTL-2 inhibitor could improve metabolic health in non-diabetic obese subjects. ${ }^{19}$ Further investigations on the exact mechanisms of SGLT2 inhibitors are needed.

The present research had certain limitations. First, the number of included studies was insufficient, especially for secondary outcomes. We were unable to adjust the possible confounders due to the small number of studies and limited information on the baseline characteristics of participants. However, the body weight reduction by SGLT2 inhibitors, which was the primary outcome of the study, remained significant after adjusting for study durations and gender, which were quite heterogeneous among trials. Furthermore, we were unable to assess the change in glycemic status (i.e., glycosylated hemoglobin or fasting plasma glucose) because only one trial reported it. We expect that in future systematic reviews and metaanalysis, the number of studies included for each effect analysis must be adequate. Second, the regimen of SGLT2 inhibitors and study duration were inconsistent among the included studies. Third, across the outcomes analyzed, although the quality of evidence was assessed using the Grading of Recommendations Assessment, there was moderate heterogeneity among studies for body weight change. Finally, the study conclusion was not entirely novel, as there have been a few reports on the weight-lowering effect of SGLT2 inhibitors in the non-diabetic population; $;^{33,34}$ nevertheless, contrary to other studies, this research found that the body weight reduction 
by SGLT2 inhibitors persisted after adjusting for study duration and gender of the participants. As a result, these findings could provide additional evidence supporting the weight-lowering benefit of SGLT2 inhibitors in obese patients without diabetes.

Among overweight or obese patients without diabetes mellitus, this study demonstrated that patients treated with SGLT2 inhibitors had significant body weight reduction compared with those who received a placebo. Future research about SGLT2 inhibitors in other subgroups of obese patients is warranted to determine their potential for the management of obesity.

\section{CONFLICTS OF INTEREST}

Chang Hee Jung is an Associate Editor of the journal. However, he was not involved in peer reviewer selection, evaluation, or decision process of this article. No other potential conflicts of interest relevant to this article were reported.

\section{ACKNOWLEDGMENTS}

This study was supported by the 2021 JOMES research grant (grant No. KSSO-J-2021001) of the Korean Society for the Study of Obesity.

\section{AUTHOR CONTRIBUTIONS}

Study concept and design: YKC and CHJ; acquisition of data: YKC and $\mathrm{CHJ}$; analysis and interpretation of data: $\mathrm{YKC}$ and $\mathrm{YJK}$; drafting of the manuscript: YKC; critical revision of the manuscript: YJK and $\mathrm{CHJ}$; statistical analysis: YKC and YJK; administrative, technical, or material support: $\mathrm{YJK}$; and study supervision: $\mathrm{CHJ}$.

\section{SUPPLEMENTARY MATERIALS}

Supplementary materials can be found via https://doi.org/10. $7570 /$ jomes 21061 .

\section{REFERENCES}

1. Nam GE, Kim YH, Han K, Jung JH, Rhee EJ, Lee SS, et al.
Obesity fact sheet in Korea, 2019: prevalence of obesity and abdominal obesity from 2009 to 2018 and social factors. J Obes Metab Syndr 2020;29:124-32.

2. NCD Risk Factor Collaboration (NCD-RisC). Worldwide trends in body-mass index, underweight, overweight, and obesity from 1975 to 2016: a pooled analysis of 2416 population-based measurement studies in 128.9 million children, adolescents, and adults. Lancet 2017;390:2627-42.

3. Ng M, Fleming T, Robinson M, Thomson B, Graetz N, Margono C, et al. Global, regional, and national prevalence of overweight and obesity in children and adults during 19802013: a systematic analysis for the Global Burden of Disease Study 2013. Lancet 2014;384:766-81.

4. Pereira MJ, Eriksson JW. Emerging role of SGLT-2 inhibitors for the treatment of obesity. Drugs 2019;79:219-30.

5. Martin-Rodriguez E, Guillen-Grima F, Martí A, Brugos-Larumbe A. Comorbidity associated with obesity in a large population: the APNA study. Obes Res Clin Pract 2015;9:435-47.

6. Sirtori A, Brunani A, Capodaglio P, Berselli ME, Villa V, Ceriani F, et al. Patients with obesity-related comorbidities have higher disability compared with those without obesity-related comorbidities: results from a cross-sectional study. Int J Rehabil Res 2016;39:63-9.

7. Simon GE, Von Korff M, Saunders K, Miglioretti DL, Crane PK, van Belle G, et al. Association between obesity and psychiatric disorders in the US adult population. Arch Gen Psychiatry 2006;63:824-30.

8. Malnick SD, Knobler H. The medical complications of obesity. QJM 2006;99:565-79.

9. DeFronzo RA, Hompesch M, Kasichayanula S, Liu X, Hong Y, Pfister $\mathrm{M}$, et al. Characterization of renal glucose reabsorption in response to dapagliflozin in healthy subjects and subjects with type 2 diabetes. Diabetes Care 2013;36:3169-76.

10. Higgins JP, Altman DG, Gøtzsche PC, Jüni P, Moher D, Oxman $\mathrm{AD}$, et al. The Cochrane Collaboration's tool for assessing risk of bias in randomised trials. BMJ 2011;343:d5928.

11. Cohen J. Statistical power analysis for the behavioral sciences. 2nd ed. Hillsdale (NJ): Lawrence Erlbaum Associates; 1988.

12. Bessesen DH, Van Gaal LF. Progress and challenges in antiobesity pharmacotherapy. Lancet Diabetes Endocrinol 2018; 
6:237-48.

13. MacLean PS, Wing RR, Davidson T, Epstein L, Goodpaster B, Hall KD, et al. NIH working group report: innovative research to improve maintenance of weight loss. Obesity (Silver Spring) 2015;23:7-15.

14. Henry RR, Klein EJ, Han J, Iqbal N. Efficacy and tolerability of exenatide once weekly over 6 years in patients with type 2 diabetes: an uncontrolled open-label extension of the DURATION-1 study. Diabetes Technol Ther 2016;18:677-86.

15. Bolinder J, Ljunggren Ö, Johansson L, Wilding J, Langkilde AM, Sjöström CD, et al. Dapagliflozin maintains glycaemic control while reducing weight and body fat mass over 2 years in patients with type 2 diabetes mellitus inadequately controlled on metformin. Diabetes Obes Metab 2014;16:159-69.

16. Del Prato S, Nauck M, Durán-Garcia S, Maffei L, Rohwedder $\mathrm{K}$, Theuerkauf A, et al. Long-term glycaemic response and tolerability of dapagliflozin versus a sulphonylurea as add-on therapy to metformin in patients with type 2 diabetes: 4-year data. Diabetes Obes Metab 2015;17:581-90.

17. Cai X, Yang W, Gao X, Chen Y, Zhou L, Zhang S, et al. The association between the dosage of SGLT2 inhibitor and weight reduction in type 2 diabetes patients: a meta-analysis. Obesity (Silver Spring) 2018;26:70-80.

18. Bays HE, Weinstein R, Law G, Canovatchel W. Canagliflozin: effects in overweight and obese subjects without diabetes mellitus. Obesity (Silver Spring) 2014;22:1042-9.

19. Napolitano A, Miller S, Murgatroyd PR, Hussey E, Dobbins RL, Bullmore ET, et al. Exploring glycosuria as a mechanism for weight and fat mass reduction: a pilot study with remogliflozin etabonate and sergliflozin etabonate in healthy obese subjects. J Clin Transl Endocrinol 2013;1:e3-8.

20. Hollander P, Bays HE, Rosenstock J, Frustaci ME, Fung A, Vercruysse F, et al. Coadministration of canagliflozin and phentermine for weight management in overweight and obese individuals without diabetes: a randomized clinical trial. Diabetes Care 2017;40:632-9.

21. He YL, Haynes W, Meyers CD, Amer A, Zhang Y, Mahling P, et al. The effects of licogliflozin, a dual SGLT1/2 inhibitor, on body weight in obese patients with or without diabetes. Diabetes Obes Metab 2019;21:1311-21.
22. Færch K, Blond MB, Bruhn L, Amadid H, Vistisen D, Clemmensen KK, et al. The effects of dapagliflozin, metformin or exercise on glycaemic variability in overweight or obese individuals with prediabetes (the PRE-D Trial): a multi-arm, randomised, controlled trial. Diabetologia 2021;64:42-55.

23. Komoroski B, Vachharajani N, Feng Y, Li L, Kornhauser D, Pfister M. Dapagliflozin, a novel, selective SGLT2 inhibitor, improved glycemic control over 2 weeks in patients with type 2 diabetes mellitus. Clin Pharmacol Ther 2009;85:513-9.

24. Komoroski B, Vachharajani N, Boulton D, Kornhauser D, Geraldes M, Li L, et al. Dapagliflozin, a novel SGLT2 inhibitor, induces dose-dependent glucosuria in healthy subjects. Clin Pharmacol Ther 2009;85:520-6.

25. Devineni D, Morrow L, Hompesch M, Skee D, Vandebosch A, Murphy J, et al. Canagliflozin improves glycaemic control over 28 days in subjects with type 2 diabetes not optimally controlled on insulin. Diabetes Obes Metab 2012;14:539-45.

26. Tyack PL, Calambokidis J, Friedlaender A, Goldbogen J, Southall B. Formal comment on Schorr GS, Falcone EA, Moretti DJ, Andrews RD (2014) first long-term behavioral records from Cuvier's Beaked Whales (Ziphius cavirostris) reveal record-breaking dives. PLoS ONE;9(3):e92633. doi: 10.1371/journal.pone.0092633. PLoS One 2015;10:e0142287.

27. Sha S, Polidori D, Heise T, Natarajan J, Farrell K, Wang SS, et al. Effect of the sodium glucose co-transporter 2 inhibitor canagliflozin on plasma volume in patients with type 2 diabetes mellitus. Diabetes Obes Metab 2014;16:1087-95.

28. Devenny JJ, Godonis HE, Harvey SJ, Rooney S, Cullen MJ, Pelleymounter MA. Weight loss induced by chronic dapagliflozin treatment is attenuated by compensatory hyperphagia in diet-induced obese (DIO) rats. Obesity (Silver Spring) 2012;20:1645-52.

29. Yokono M, Takasu T, Hayashizaki Y, Mitsuoka K, Kihara R, Muramatsu Y, et al. SGLT2 selective inhibitor ipragliflozin reduces body fat mass by increasing fatty acid oxidation in highfat diet-induced obese rats. Eur J Pharmacol 2014;727:66-74.

30. Busch RS, Kane MP. Combination SGLT2 inhibitor and GLP-1 receptor agonist therapy: a complementary approach to the treatment of type 2 diabetes. Postgrad Med 2017;129: 686-97. 
31. Ferrannini E, Baldi S, Frascerra S, Astiarraga B, Heise T, Bizzotto $\mathrm{R}$, et al. Shift to fatty substrate utilization in response to sodium-glucose cotransporter 2 inhibition in subjects without diabetes and patients with type 2 diabetes. Diabetes 2016;65: 1190-5.

32. Finucane FM, Luan J, Wareham NJ, Sharp SJ, O’Rahilly S, Balkau B, et al. Correlation of the leptin:adiponectin ratio with measures of insulin resistance in non-diabetic individuals. Diabetologia 2009;52:2345-9.
33. Wong J, Chan KY, Lo K. Sodium-glucose co-transporter 2 inhibitors on weight change and cardiometabolic profiles in individuals with overweight or obesity and without diabetes: a meta-analysis. Obes Rev 2021;22:e13336.

34. Zheng H, Liu M, Li S, Shi Q, Zhang S, Zhou Y, et al. Sodiumglucose co-transporter-2 inhibitors in non-diabetic adults with overweight or obesity: a systematic review and meta-analysis. Front Endocrinol (Lausanne) 2021;12:706914. 